\section{Dose-response relationship between alcohol use and blood pressure among drivers of commercial vehicles in Calabar, Southern Nigeria}

\author{
Segun Bello, ${ }^{1,2}$ Akinolu Fatiregun, ${ }^{3}$ \\ Angela Oyo-Ita, ${ }^{1,2}$ Bassey Ikpeme ${ }^{1}$ \\ 'Department of Community Medicine, \\ University of Calabar Teaching, Calabar, \\ Nigeria; \\ 2Institute of Tropical Diseases Research \\ and Prevention, University of Calabar \\ Teaching Hospital, Calabar, Nigeria; \\ ${ }^{3}$ Department of Epidemiology, \\ Biostatistics and Environmental Health, \\ Faculty of Public Health, University \\ of Ibadan, Ibadan, Nigeria
}

\section{Introduction}

Alcohol is a sedative/hypnotic with effects similar to those of barbiturates. ${ }^{1}$ The type of alcoholic beverages consumed depends on the social context and financial capability. Alcoholic beverages may be in form of beer, wine, dry gin. Drinking alcohol is an activity that many people enjoy; taking a few drinks occasionally is generally harmless. Most people do not have problems as a result of drinking alcohol in this manner, although this may predispose to heavy use.

Heavy alcohol consumption has been shown in observational studies to have a strong positive association with elevated blood pressure. ${ }^{2-4}$ Further evidence have been shown by clinical trials $^{5,6}$ that have demonstrated that reduction in alcohol intake among individuals who drink heavily (i.e. three or more drinks per day) can lower blood pressure in normotensive and hypertensive men.

Some studies have recorded a linear doseresponse relationship sometimes starting with a consumption threshold of three drinks per day (30 $\mathrm{g}$ of ethanol) ${ }^{7-13}$ In others, the relationship has been non-linear especially in women, and some authors have speculated that ingestion of small quantities may reduce blood pressure. ${ }^{14-22}$ These discrepancies may reflect differences in investigational design, methods and populations. ${ }^{23}$ Many studies have been done in this area in developed countries like the United States, United Kingdom and Australia. This is however, not a commonly researched area in this part of the world. The aim of this study was to assess the relationship between alcohol consumption and blood pressure of drivers of commercial vehicles.

\section{Materials and Methods}

\section{Study design \\ The study was cross-sectional descriptive.}

\section{Study area}

Calabar is the capital city of Cross River State. It is located in South-south region of Nigeria. Calabar is located between latitude 4' 58 North and longitude 8' 17 East and is within the tropical rain forest. Relative humidity is $84 \%$ with mean annual temperature of $79^{\circ} \mathrm{F}$ and average rainfall of $307.6 \mathrm{~cm}$. Calabar is bounded in the north by Odukpani Local Government Area, in the west by Calabar River, in the south and east by Qua River. Efik is the most widely spoken language, while Christianity is the most predominant religion in the study settings. From the 2007 National Population Commission (NPC) enumeration of motors parks, Calabar has 21 short distance drivers' motor parks and 11 long distance drivers motor parks.

\section{Study population}

The study population included long distance and short distance drivers in Calabar and their assistants (if any) who travel with them. Long distance drivers as used here were those not being able to make a return journey on the same day, whenever they travelled, because of the distance of their destination.

Sample size was calculated using the LeslieKish formula for single proportion and a $\mathrm{P}$ value of $67.5 \%$ obtained from a similar study in Ile-Ife, Nigeria. ${ }^{24}$ An allowance of $15 \%$ was made for incomplete questionnaire. Sample size required was 337 .

\section{Sampling technique}

The sample size was stratified into two, the long distance and the short distance drivers according to the sampling fraction of 1:1.5 obtained from the 2007 NPC enumeration. Eight out of 11 long distance drivers' parks were selected by simple ballot and 10 of the 21 short distance drivers' parks were selected to reach adequate sample size. Sixteen clusters (6 long distance and 10 short distance parks) were initially selected, but two additional long distance parks had to be added to make up enough respondents. All drivers met at the time of visits to selected clusters were interviewed.

\section{Data collection}

An interviewer administered, pre-tested, semi-structured questionnaire was used to collect data from respondents. Questionnaire was pre-tested among 20 commercial motorcyclists
Correspondence: Segun Bello,

Department of Community Medicine, University of Calabar Teaching, Calabar, Nigeria.

E-mail: drsegunbello@yahoo.com

Key words: Alcohol use, Blood pressure, AUDIT.

Received for publication: 28 July 2010.

Revision received: 11 August 2010.

This work is licensed under a Creative Commons Attribution 3.0 License (by-nc 3.0).

CC Copyright S. Bello et al., 2010

Licensee PAGEPress, Italy

Journal of Public Health in Africa 2010; 1:e5

doi:10.4081/jphia.2010.e5

in Calabar. The questionnaire contained questions on the socio-demographic characteristics of respondents, questions of the WHO Alcohol Use Disorders Identification Test (AUDIT, interview version) ${ }^{25}$ The AUDIT is a widely used screening instrument to detect hazardous and harmful alcohol consumption. It has a high level of validity and reliability. A score of eight or higher is considered a positive screen. ${ }^{25,26}$ The ten questions from AUDIT scored frequency (item 1) and quantity (item 2) of alcohol use, frequency of bingeing (heavy episodic consumption) (item 3), and consequences (dependence/incipient dependence [items 4-6] and alcohol-related harm [items 7-10]) of alcohol consumption. All ten items were given scores ranging from zero to four in the generic tool depending on the response. A composite score was generated from the ten items according to the guideline and a respondent scoring eight or more was identified as hazardous alcohol user. Alcohol users who scored below eight were identified as harmless users. ${ }^{25}$ Appropriate code was given to each questionnaire to distinguish long distance drivers from short distance drivers. Data collection was done by trained research assistants and supervised by the principal investigator. Data editing was done on the field by the principal investigator.

The sitting blood pressure of respondents was taken twice within an interval of $30 \mathrm{~min}$ utes and the average of systolic and diastolic blood pressure calculated and recorded for each participant. We made use of the mercury sphygmomanometer. All blood pressure measurements were done by the principal investigator.

Data was entered, cleaned and analyzed using Statistical Package for Social Sciences (SPSS) version 14.0.

Ethical approval was sought and obtained from the joint Ethics Review Committee of the University of Calabar and University of Calabar Teaching Hospital. 


\section{Results}

All respondents were males with mean age of $38.5 \pm 9.5$ years. Overall, 304 (84.4\%) of respondents took alcoholic drink. The mean age of onset of alcohol use was $20.9 \pm 7.7$ years. Two hundred and eighty (90.9\%) used beer, 236 (76.6\%) used palm wine, while 128 (41.6\%) used spirit/gin. Thirty-two (10.5\%) of the respondents drank monthly or less, 84 (27.6\%) drank two to four times a month, $116(38.2 \%)$ drank two to three times a week, while 60 (19.7\%) used alcoholic beverages four times or more a week. Two hundred and eight (70.3\%) took one or two drinks (10-20 g alcohol content $)^{24}$ on a typical day, $60(20.3 \%)$ took three or four drinks, 20 (6.8\%) took five or six drinks, 4 (1.4\%) took seven, eight or nine drinks while 4 (1.4\%) took ten or more drinks on a typical day. Two hundred and twenty-four (73.7\%) had never indulged in heavy episodic drinking (i.e. six or more drinks on one occasion), ${ }^{24} 16$ (5.3\%) indulged less than monthly, 28 (9.2\%) indulged monthly, 28 (9.2\%) indulged weekly, while 8 (2.6\%) indulged daily or almost daily (Figure 1).

\section{Alcohol use and blood pressure}

An independent t-test was conducted first to investigate the presence of significant baseline difference in the ages of alcohol users and nonusers. This is because age is a confounding factor in the relationship between alcohol use and blood pressure. The mean age of alcohol users was $38.08 \pm 9.30$ years and for non-users was $40.5 \pm 10.7$ years. There was no significant difference in the mean ages of alcohol users and non-users ( $\mathrm{t}=-1.750, \mathrm{P}=0.81$ ) (Table1).

The mean systolic blood pressure (SBP) of alcohol users was $129.8 \pm 15.1 \mathrm{mmHg}$, while for non-users, it was $119.6 \pm 10.8 \mathrm{mmHg}$. The mean systolic blood pressure of alcohol users was significantly higher than the mean systolic blood pressure of non-users $(\mathrm{t}=4.82, \mathrm{P}<0.001)$.

The mean diastolic blood pressure (DBP) of alcohol users was $84.3 \pm 9.7 \mathrm{mmHg}$ while for non-users, mean DBP was $77.1 \pm 8.0 \mathrm{mmHg}$. The mean DBP of alcohol users was significantly higher than the mean DBP of non-users $(\mathrm{t}=5.186, \mathrm{P}<0.001)$.

Respondents' blood pressure was also analyzed along the three categories of AUDIT classification, i.e. non-users, harmless users and hazardous users (Table 2).

F-ratio for ANOVA of SBP was 9.668, $\mathrm{P}<0.001$. Post-hoc analysis showed that the mean SBP of hazardous users was significantly higher than mean SBP of harmless users $(\mathrm{P}=0.005)$, which in turn was significantly higher than mean SBP of non-users $(\mathrm{P}=0.017)$. The mean SBP of hazardous users was also significantly higher than the mean SBP of nonusers $(\mathrm{P}<0.001)$. This shows a dose-response relationship between alcohol use and blood

Table 1. Categories of respondents by alcohol use.

\begin{tabular}{lcc} 
Categories of respondents & Frequency & Percentage (\%) \\
Non-users & 72 & 20.0 \\
Harmless users & 204 & 56.7 \\
\hline Hazardous users & 84 & 23.3 \\
Total & 360 & 100 \\
\hline
\end{tabular}

Table 2. Mean and standard deviation of systolic blood pressure and diastolic blood pressure of non-users, harmless and hazardous users.

\begin{tabular}{lccccc} 
Class & N & $\begin{array}{c}\text { Mean } \\
\text { SBP } \\
(\mathbf{m m H g})\end{array}$ & $\begin{array}{c}\text { Standard } \\
\text { deviation } \\
\text { SBP } \\
(\mathbf{m} \text { mHg) }\end{array}$ & $\begin{array}{c}\text { Mean } \\
\text { DBP } \\
(\mathbf{m m H g})\end{array}$ & $\begin{array}{c}\text { Standard } \\
\text { deviation } \\
\text { DBP } \\
(\mathbf{m m H g})\end{array}$ \\
Non-users & 72 & 123.0 & 10.7 & 79.4 & 8.5 \\
Harmless users & 204 & 127.9 & 15.6 & 82.7 & 9.9 \\
\hline Hazardous users & 84 & 133.5 & 15.2 & 87.6 & 9.2 \\
\hline
\end{tabular}

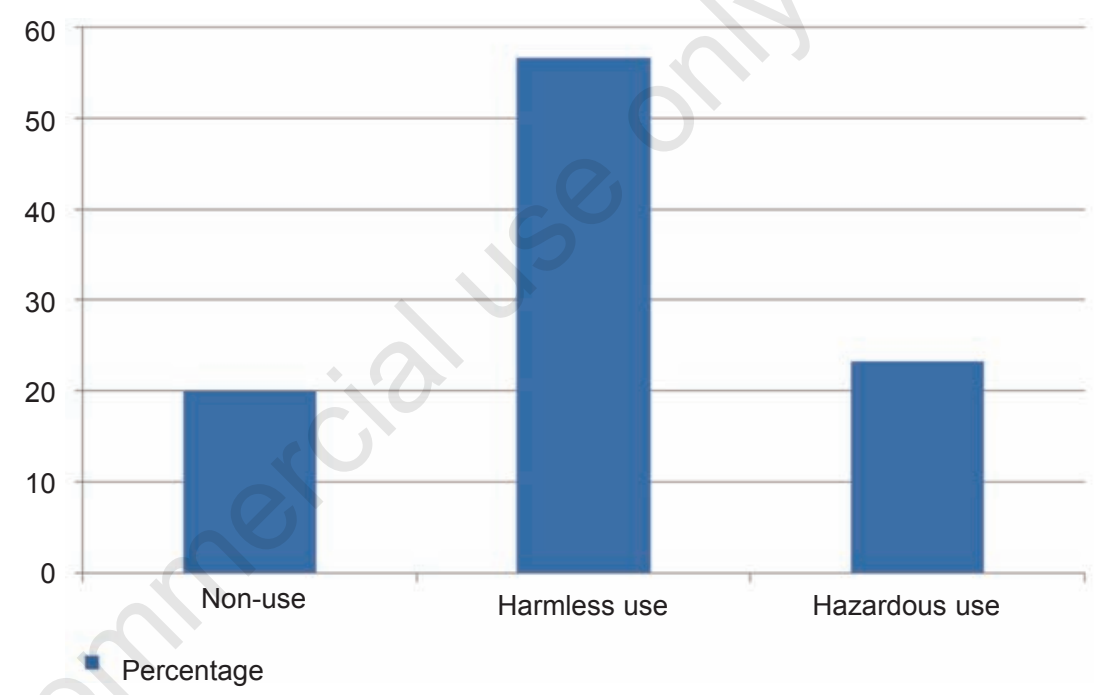

Figure 1. Diagram illustrating proportion of respondents by category of alcohol use.

pressure. A similar result was obtained for the DBP (F-ratio=14.091, P<0.001). The mean DBP of hazardous users was significantly higher than the mean DBP of harmless users $(\mathrm{P}=0.013)$, which in turn was significantly higher than the mean DBP of non-users $(\mathrm{P}=0.013)$. The mean DBP of hazardous users was also significantly higher than the mean DBP of non-users $(\mathrm{P}<0.001)$.

\section{Discussion}

There are very few studies on alcohol consumption and its consequences in this part of the world as it is generally believed that the burden of the disease is basically that of the developed countries, where alcohol is consumed in large quantities. But lifestyles are fast changing as many developing countries are adopting the lifestyles of the western culture; there is also epidemiological transition as developing countries now have to contend with the changing pattern of disease burden. More than before, non-communicable diseases are beginning to contribute significantly to disease burden in this part of the world.

The findings of this study showed that blood pressure of participants was related in a linear dose-response relationship with alcohol consumption. The classification of participants in this study was ordinal showing a gradation from non-users, harmless users to harmful users. Both the systolic and the diastolic blood pressure increased significantly in a dose-response manner across these categories, according to the quantity of alcohol consumed. This result has been widely reported in many studies that have used similar or different designs. Fuchs et al. in a longitudinal/cohort study ${ }^{23}$ conducted among 8334 (of the 15,792 persons enrolled in the Arterosclerosis Risk in the Communities study in USA) aged 45 to 64 years, found that 
the consumption of low to moderate amounts of alcohol was associated with a higher risk of hypertension in black men in America. Systolic and diastolic blood pressures were higher in black men who consumed low to moderate amounts of alcohol compared with the non-consumers, but not in 3 other race-gender strata (black women, white men and white women). Higher levels of consumption of all types of alcoholic beverages were associated with a higher risk of hypertension for all race-gender strata. The consumption of alcohol in amounts $\geq 210$ grams per week was reported as an independent risk factor for hypertension in free-living North American populations. The result of the study of Fuchs et al. may suggest a similar response pattern in all black males, as this compares very well with our study. In a randomized crossover design by Puddey et al. in Australia, 44 males experienced a reduction in blood pressure after decreasing alcohol intake. Reduction in alcohol intake was noted to contribute independently to the fall in both the systolic and diastolic blood pressure. ${ }^{5}$

Using a classification that was similar to AUDIT, Klaisky et al. classified respondents into non-drinkers, two or fewer drinks per day, three to five drinks per day or six or more per day. Both women and men who took three or more drinks per day reportedly had higher systolic and diastolic blood pressures. ${ }^{4}$ A similar result was demonstrated in the study by Fortmann et al. ${ }^{7}$ The Nurses study II conducted in the United States among 70,891 women aged 25 to 42 years also showed that daily alcohol consumption beyond two drinks per day was associated with an increase risk of hypertension. In this study, we did not adjust for other covariates of high blood pressure. This may have over-estimated the relationship, although it is not likely that the impact would have significantly changed the direction of effect, as it has been demonstrated by most previous studies that adjusting for other covariates of blood pressure like age, weight, race, smoking, coffee use, educational attainment and adioposity, did not affect the relationship between alcohol use and blood pressure. ${ }^{4,723}$ It implies that alcohol use independently increased the blood pressure in a dose-response manner.

Several hypotheses have been proposed as underlying mechanisms of action of alcohol through which it increases the blood pressure. These include its effects on the renninangiotensin-aldosterone system, impact on the adrenergic system, heart rate variability, cortisol secretion or insulin sensitivity. ${ }^{23}$ However, none of these has been able to fully explain the relationship. The findings of our study have implications in practice. The protective effect of moderate alcohol consumption on cardiovascular mortality has been well researched and reported. ${ }^{4}$ Public health and medical practitioners should carefully weigh this against the potential of alcohol to cause hypertension in giving health education and individual patient counseling. There is also need for further research into this area in this part of the world.

\section{References}

1. World Health Organization. 2008, Lexicon of alcohol and drug terms. www.who.int

2. Stamler J, Caggiula AW, Grandits GA. Relation of body mass and alcohol, nutrient, fiber, and caffeine intakes to blood pressure in the special intervention and usual care groups in the Multiple Risk Factor Intervention Trial. Am J Clin Nutr 1997; 65(suppl):338S-365S.

3. Klatsky AL, Friedman GD, Armstrong MA. The relationships between alcoholic beverage use and other traits to blood pressure: a new Kaiser Permanente study. Circulation 1986;73:628-36.

4. Klatsky AL, Armstrong MA, Friedman GD. Risk of cardiovascular mortality in alcohol drinkers, ex-drinkers and nondrinkers. Am J Cardiol 1990;66:1237-42.

5. Puddey IB, Beilin LJ, Vandongen R, et al. Evidence for a direct effect of alcohol consumption on blood pressure in normotensive men. A randomized controlled trial. Hypertension 1985;7:707-13.

6. Puddey IB, Beilin LJ, Vandongen R. Regular alcohol use raises blood pressure in treated hypertensive subjects: a randomised controlled trial. Lancet 1987;1:647-51.

7. Fortmann SP, Haskell WL, Vranizan K, et al. The association of blood pressure and dietary alcohol: differences by age, sex, and estrogen use. Am J Epidemiol 1983;118 :497-507.

8. Dyer AR, Cutter GR, Liu K, et al. Alcohol intake and blood pressure in young adults: the CARDIA Study. J Clin Epidemiol 1990; 43:1-13.

9. Strogatz DS, James SA, Haines PS, et al. Alcohol consumption and blood pressure in black adults: the Pitt Count Study. Am J Epidemiol 1991;133:442-50.

10. Klatsky AL, Friedman GD, Armstrong MA. The relationships between alcoholic beverages use and other traits to blood pressure: a new Kaiser-Permanent Study. Circulation 1986;73:628-36.

11. Lang T, Degoulet P, Aime F, et al. Relationship between alcohol consumption and hypertension prevalence and control in a French population. J Chronic Dis 1987; 40:713-20.

12. Trevisan M, Krogh V, Farinaro E, et al. Alcohol consumption, drinking pattern and blood pressure: analysis of data from the Italian National Research Council Study. Int J Epidemiol 1987;16:520-7.
13. Keil U, Chambless L, Filipiak B, Härtel U. Alcohol and blood pressure and its interaction with smoking and other behavioural variables: results from the MONICA Augsburg Survey 1984-1985. J Hypertens 1991;9:491-8.

14. Gordon T, Kannel WB. Drinking and its relation to smoking, blood pressure, blood lipids and uric acid: the Framingham Study. Arch Intern Med 1983;143:1366-74.

15. Weissfeld LJ, Johnson EH, Brock BM, Hawthorne VM. Sex and age interactions in the association between alcohol and blood pressure. Am J Epidemiol 1988;128:559-69.

16. Moore RD, Levine DM, Southard J, Entwisle G, Shapiro S. Alcohol consumption and blood pressure in the 1982 Maryland Hypertension Survey. Am J Hypertens 1990;3:1-7.

17. Gilman MW, Cook NR, Evans DA, et al. Relationship of alcohol intake with blood pressure in young adults. Hypertension 1995;25:1106-10.

18. Jackson R, Stewart A, Beaglehole R, Scragg R. Alcohol consumption and blood pressure. Am J Epidemiol 1985;122:1037-44.

19. Klatsky AL, Friedman GD, Siegelaub AB, Gérard MJ. Alcohol consumption and blood pressure: Kaiser-Permanent Multiphasic Health Examination data. N Engl J Med 1977;296:1194-2000.

20. Harburg E, Ozgoren F, Hawthorne VM, Schork MA. Community norms of alcohol usage and blood pressure: Tecumseh, Michigan. Am J Public Health 1980;70 :81320.

21. Maheswaran R, Gill JS, Davies P, Beevers DG. High blood pressure due to alcohol: a rapidly reversible effect. Hypertension 1991;17(6 Pt 1):787-92.

22. Keil U, Chambless L, Remmers A. Alcohol and blood pressure: results from the Luebeck Blood Pressure Study. Prev Med 1989;18:1-10.

23. Fuchs FD, Chambless LE, Whelton PK, et al. Alcohol consumption and the incidence of hypertension: the Arterosclerosis risk in communities study. Hypertension 2001; 37:1242-50.

24. Abiona TC, Aloba 00, Fatoye F0. Pattern of alcohol consumption among commercial road transport workers in a semi-urban community in south western Nigeria. East Afr Med J 2006;83:494-9.

25. World Health Organization 2001. The Alcohol Use Disorders Identification Test: guidelines for use in primary care. 2nd edition, pp 17-21.

26. Zakhari S, Li T. Determinants of Alcohol use and Abuse. Impact of quantity and frequency patterns on liver disease. Hepatology 2007;46:2032-9. 